\title{
Evaluating the Representation of Cultural Elements in an In-use EFL Textbook
}

\author{
Nazli Bahrami \\ Department of English Teaching, Najafabad Branch, Islamic Azad University, Esfahan, Iran \\ E-mail: nzl.bahrami@gmail.com
}

Doi:10.7575/aiac.alls.v.6n.3p.128

URL: http://dx.doi.org/10.7575/aiac.alls.v.6n.3p.128
Received: 02/02/2014

Accepted: 10/04/2015

\begin{abstract}
The present study was an attempt to evaluate and specify teachers' perception of the cultural elements of Total English book series. Another objective was to study the techniques and strategies that teachers usually use in teaching these elements. To this end, a total of 50 male and female teachers working at Kish Language Institute in Esfahan participated in the study. A questionnaire adopted from Kilickaya (2004) was used for studying teachers' perception. It included 25 items about cultural elements. Some more cultural related options were added to the questionnaire later. An observation scheme was also used to observe teachers' activities in the classroom. After the analysis of the data, it was found that the Total English Series is biased as it promotes the western culture and values much more than other cultures. Moreover, the cultural elements were mostly incompatible with the L1 (Iranian) culture. Last but not least, it was found that the English teachers working in Kish Language Centers do not have a good command of target culture (L2), and use limited number of activates to introduce cultural elements of the books.
\end{abstract}

Keywords: Cultural elements, Source culture, Target culture, Textbook evaluation

\section{Introduction}

Nowadays one of the most important subjects in the field of linguistics and language teaching is the relationship between education, ideology and power. Different researchers have done studies on how Textbooks serve as the medium that spread socially accepted knowledge, controls and legitimizes it. In this regard the process of education and learning is equal with the accumulation of this regulated knowledge as Apple (1993) discussed it. He believes the achievement of power, then, is seen to be the goal of education, which is interpreted as the right to name the world.

Cultural content plays a crucial role in selecting any EFL textbook and in order to bring a multicultural awareness into the brains of EFL learners. To increase students' intercultural experiences and strategies some careful thought and attention should be given to this content. Evaluating EFL textbooks can show curriculum planners, syllabus designers, supervisors, evaluators, teachers and consumers the very important role of relating the cultural content and its source materials to the textbooks' objectives and EFL learners' interests. Specially, (Dweik, 1986) has recommended that "students should not read about materials for the sake of only reading, they should read materials that appeal to their interests and be pleased by reading them."(P.99). Since in teaching learning process EFL textbooks are the main medium achieving evaluation steps may show the Importance of integrating culture with second language teaching. A textbook which enjoys cultural appropriateness is able to find a common ground between the real cultural content of the EFL textbooks and what EFL teachers may misunderstand about the it. In other words it is essential for EFL teachers to carefully evaluate the cultural content of materials and textbooks they use since these materials may potentially impact EFL learners' understanding of foreign culture and ruin one of the main competencies students need to have which is to communicate the cultural content. In order to improve students' four language skills the resource materials should be compatible with the content of the EFL textbooks, the English teacher uses and to add rich meaning to the content. Moreover, from what has been presented before about the relationship between culture and language, one could support the predominant view of seeing culture teaching as an integral part of language teaching.This relation, however, was stated several decades ago. Most scholars in language teaching had the assumption that learning a language means "acquiring the set of pragmatic norms and cultural values embodied in the target language" (Zhang and Yan, 2006, p. 72). Culture teaching can also increase communicative competence. Sociolinguist Dell Hymes made the term Communicative Competence (CC) up first in 1967. He was not satisfied with Chomsky's notion of competence therefore he gave a new perspective of (CC) as "that aspect of our competence that enables us to convey and interpret messages and to negotiate meanings interpersonally within specific context" (Brown, 2007, p. 219).

\subsection{The advantages of cultural elements in EFL textbooks}

From what has been presented before about the relationship between culture and language, one could support the predominant view of seeing culture teaching as an integral part of language teaching.

This relation, however, was stated several decades ago. Most scholars in language teaching had the assumption that learning a language means "acquiring the set of pragmatic norms and cultural values embodied in the target language" (Zhang and Yan, 2006, p. 72) 


\subsection{Statement of the Problem}

In EFL education according to Cortazzi and Jin (1999) "A textbook can be a teacher, a map, a resource, a trainer, an authority, and an ideology". Therefore it is inevitable to examine textbooks considering the statements arguing the infusion of culture in EFL pedagogy with respect tp the significant roles they play in learning process in the classroom. Textbooks all around the world have different cultural positions; they might be based on source culture, target culture or international cultures. Hence, besides providing linguistic and topical content, the textbook can be the major source of cultural elements. The different cultural orientations mentioned above refer to students' own culture, the culture in which the target language is used as a first language while the last one, international cultures, refers to variety of cultures in English and non-English-speaking countries. Consequently, this categorization will assist in describing the cultural orientation of the textbooks. This categorization can help evaluating the cultural content of the textbooks.

Misinterpretations in EFL classrooms often caused by cross-cultural awareness EFL learners lack. Culture dictates many rules in the class and influences effective interactions. As Powel and Anderson (1994) claimed in their study when a female muslim learner does not volunteer to lead a group while other members of the group are males or in cases she avoids eye-contact with a male teacher, he should not be surprised since it is the matter of her up-bringing culture and is undesirable in the Islamic context. A teacher who does not have the cultural awareness and understanding may criticise the learner for breaking the ideals of communicating effectively. In order to manage the classroom effectively which affects the teaching learning process, it would be necessary for the teacher to have this cross-cultural understanding. Therefore it would be much easier for the teacher to manage the teaching and learning process by focusing on special aspects of culture while considering the values of the local culture. This is what McLeod (1985) asserts, "It is important for the teacher to understand the values he is transmitting and also the values of the students' cultures" Generally the fact that the culture a person is born in is true most of the times can cause incompatible feelings among people who are engaged in cross-cultural interactions. Therefore, the textbooks utilized in the major language centers in Iran such as Kish must be carefully scrutinized culturally to avoid problems, which in turn may lead some cultural

clashes. Regarding all of the above-mentioned issues, Total English series, which are popular ESL textbook series worldwide, were taken into consideration for analysis. These books are published by Longman Publications and are being taught in all Kish Language Institute branches all over Iran. Therefore, a fine-grained analysis of the books regarding hegemonic cultural elements seemed vital as they are widely used nationwide. In the present study, four levels of these textbooks including: Elementary, Pre-intermediate, Intermediate and Upper-intermediate were used to be analyzed according to the cultural elements represented in them such as: Life style, Historical, Geographical, Social, Economical elements, etc. The purpose of the analysis was therefore threefold: first, it was done to investigate the possible hegemonic aspects represented in the Total English textbooks. It is very important that a textbook used in popular institutes be compatible with the cultural elements of the target culture (L1) to avoid cultural clashes and ensure reasonable learning outcomes. If the cultural values promoted in Total English books and other similar educational textbooks are incompatible with the norms of L2 learners, then there will be some cultural clashes. The lack of such thorough analysis concerning the cultural appropriateness of the content and the possible hegemonic approach of the books made the present study necessary to be carried out.

Besides, to have a more comprehensive evaluation of the books, teachers' perceptions were also taken into consideration. Teachers' perception was almost neglected in other textbook analyses conducted so far (Brown, 2007). Finally, the ways by which teachers would present such cultural elements in the class was so important and hard no neglect. Based on a survey conducted by Barker (2003), many teachers either do not have a good command of cultural elements to convey them to their students, or they do not use a variety of interesting tasks to work on cultural values as a part of their teaching schedule. As a result, this important factor was looked into as a part of a comprehensive Total English Book analysis to identify the possible weaknesses in this regard.

\subsection{Research Questions}

In order to address the challenges and shortcomings of the related studies in the field of teaching cultural issues, by considering the aforementioned problems and purposes, this study was conducted to provide answers to the following research questions:

\section{RQ1. What are teachers' perceptions of cultural topics and elements represented in Total English textbooks?}

\section{RQ2. What are the techniques and strategies that teachers use to teach cultural elements?}

\section{Research Design}

To conduct this study, the researcher used a survey design to answer the first and second research questions coupled with a thorough text analysis of different chapters afterwards.

\subsection{Participants}

A total of 50 male and female teachers working at Kish Language Institute (two branches) in Isfahan participated in the study to fill in a Cultural Checklist. The teachers were almost in their 20s and had three years of teaching experience on average. Most of them held either a masters' degree or they were still doing their masters in applied linguistics or translation. Less than twenty percent of them had bachelors' degree, however, they had at least three years of teaching experience. Specifically, the 50 participants were comprised of 30 females $(60 \%)$ and 20 males $(40 \%)$. Ten teachers composed of six female $(60 \%)$ and four male $(40 \%)$, were randomly observed regarding the treatment they apply to 
expose students to different elements of culture represented in the books. All of the participants had at least two or more years' of experience in teaching English as a foreign language. They ranged in age from 20 to 40.

\subsection{The Teacher Questionnaire}

To measure the representation of cultural elements in an in-use EFL textbook called Total English book series, the researcher used the questionnaire adopted from Kilickaya (2004), which included 25 items about cultural elements. Some more cultural related options were added to the questionnaire later. The items evaluate the supposed utilization of cultural elements, which are related to teaching the target culture.

\subsection{The Procedure}

To answer the first research question, the researcher analyzed the four textbooks of Total English series according to the "Guidelines to evaluate a textbook" by Kilickaya, (2004), found in Appendix 1. Based on the guidelines, three chapters from each book were randomly chosen to be scrutinized from a cultural perspective. Then the units were meticulously analyzed for their cultural elements and their possible differences with the learners' culture (L1). Moreover, the researcher looked into the hegemonic approach of the series and they ways in which such western cultural values were promoted. Therefore, first, the analysis and judging stage was completed. In the survey stage, the researcher examined the three randomly chosen units of Total English Book Series based on their organization, method of presentation, as well as the range and kind of materials that the book includes concerning cultural issues.

In addition, the researcher analyzed teacher's manual to see how they provide additional topics. For instance, the following cultural factors were the subject of analysis: Subject matter (topics, contexts), Vocabulary, Exercises, Illustrations, Physical make-up (cover, size, binding ...etc). In the analysis of the books, all activities were categorized based on the target culture (L2), the source culture (L1), the international culture (cultural factors related to different countries) as well as cultural free classifications (book activities with no cultural orientations). The researcher would also record any cultural related materials and analyze its compatibility with the source culture (L1) for each unit. To ensure the reliability of the answers, another expert-teacher analyzed the books and the responses were compared.

To answer the second research question, then, the checklist, found in appendix 2, was given to the respected teachers teaching different books. This was done for the sake of triangulation of the data, which improved the reliability of the evaluation. In so doing, the researcher, first, had a meeting with language teachers of "Kish Language Institute" to explain the pedagogical goals of the survey and ask them to fill the checklist out. To this end, 50 teachers agreed to participate in the study. Teachers reported perceptions were compared and analyzed by the researcher to find any possible patterns in their answer.

For the third research question, however, the researchers conducted 900 minutes of observation during a summer semester of Kish Language Center in Isfahan being ten sessions overall. The researcher would ask for the permission of the teacher to observe the class. After that, the researcher would record any cultural related activities carried out during a session on the observation scheme designed to evaluate textbooks. Moreover, a voice recorder was used to record all the conversations in different observation sessions. The conversations were then analyzed for their cultural elements and teachers' role to expose students to them. The notes would also be analyzed to find a pattern in the strategies and techniques used in the class.

\section{Teachers' Perception of Cultural Elements}

In order to answer the first research question stating,"What are teachers' perception of cultural topics and elements represented in Total English Series?" the researcher used the questionnaire adopted from Kilickaya (2004), which includes 25 items about cultural elements. In this questionnaire, the items evaluate the supposed utilization of cultural elements, which are related to teaching the target culture. The teachers' answer to each item was submitted to SPSS software and analyzed one by one to get a fine grained analysis of Total English Series cultural elements. In the following section, each item will be analyzed thoroughly.

Table 1. The distribution of answers for all items

\begin{tabular}{|c|c|c|c|c|c|c|}
\hline $\begin{array}{l}\text { Questions } \\
\text { (items) }\end{array}$ & SD & $\begin{array}{c}\text { Completely } \\
\text { agree }\end{array}$ & Agree & No opinion & Disagree & $\begin{array}{c}\text { Completely } \\
\text { Disagree }\end{array}$ \\
\hline 1 & 4.28 & 5 & 11 & 17 & 11 & 6 \\
\hline Percentage & & $10 \%$ & $22 \%$ & $34 \%$ & $22 \%$ & $12 \%$ \\
\hline 2 & 9.1 & 0 & 17 & 22 & 6 & 5 \\
\hline Percentage & & $0 \%$ & $34 \%$ & $44 \%$ & $12 \%$ & $10 \%$ \\
\hline 3 & 13.5 & 16 & 34 & 0 & 0 & 0 \\
\hline Percentage & & $32 \%$ & $68 \%$ & $0 \%$ & $0 \%$ & $0 \%$ \\
\hline 4 & 6.3 & 6 & 22 & 6 & 11 & 5 \\
\hline Percentage & & $12 \%$ & $44 \%$ & $12 \%$ & $22 \%$ & $10 \%$ \\
\hline 5 & 9.65 & 0 & 28 & 11 & 6 & 5 \\
\hline Percentage & & $0 \%$ & $56 \%$ & $22 \%$ & $12 \%$ & $10 \%$ \\
\hline 5 & 8.17 & 0 & 28 & 11 & 6 & 5 \\
\hline Percentage & & $0 \%$ & $56 \%$ & $22 \%$ & $12 \%$ & $10 \%$ \\
\hline 5 & 9.65 & 0 & 28 & 11 & 6 & 5 \\
\hline
\end{tabular}




\begin{tabular}{|c|c|c|c|c|c|c|}
\hline \multirow{2}{*}{\multicolumn{2}{|c|}{$\begin{array}{l}\text { ALLS 6(3):128-137, } 2015 \\
\text { Percentaoe }\end{array}$}} & \multirow{2}{*}{$0 \%$} & \multirow{2}{*}{$56 \%$} & & & \\
\hline & & & & & $12 \%$ & \\
\hline 8 & 7.23 & 11 & 6 & 22 & 11 & 0 \\
\hline Percentage & & $22 \%$ & $12 \%$ & $44 \%$ & $22 \%$ & $0 \%$ \\
\hline 9 & 8.17 & 6 & 17 & 5 & 22 & 0 \\
\hline Percentage & & $12 \%$ & $34 \%$ & $10 \%$ & $22 \%$ & $0 \%$ \\
\hline 10 & 11.71 & 5 & 6 & 0 & 33 & 6 \\
\hline Percentage & & $10 \%$ & $12 \%$ & $0 \%$ & $66 \%$ & $12 \%$ \\
\hline 11 & 8.46 & 2 & 17 & 0 & 22 & 9 \\
\hline Percentage & & $4 \%$ & $34 \%$ & $0 \%$ & $44 \%$ & $18 \%$ \\
\hline 12 & 12.08 & 2 & 4 & 0 & 33 & 11 \\
\hline Percentage & & $4 \%$ & $8 \%$ & $0 \%$ & $66 \%$ & $22 \%$ \\
\hline 13 & 8.31 & 16 & 23 & 6 & 5 & 0 \\
\hline Percentage & & $32 \%$ & $46 \%$ & $12 \%$ & $10 \%$ & $0 \%$ \\
\hline 14 & 10.73 & 6 & 28 & 16 & 0 & 0 \\
\hline Percentage & & $0 \%$ & $34 \%$ & $44 \%$ & $12 \%$ & $10 \%$ \\
\hline 15 & 9.65 & 6 & 28 & 5 & 11 & 0 \\
\hline Percentage & & $12 \%$ & $46 \%$ & $10 \%$ & $22 \%$ & $0 \%$ \\
\hline 16 & 2 & 11 & 11 & 11 & 6 & 11 \\
\hline Percentage & & $22 \%$ & $22 \%$ & $22 \%$ & $12 \%$ & $22 \%$ \\
\hline 17 & 4.04 & 12 & 16 & 11 & 6 & 5 \\
\hline Percentage & & $24 \%$ & $32 \%$ & $22 \%$ & $12 \%$ & $10 \%$ \\
\hline 18 & 9.09 & 0 & 0 & 16 & 23 & 11 \\
\hline Percentage & & $0 \%$ & $0 \%$ & $32 \%$ & $46 \%$ & $22 \%$ \\
\hline 19 & 5.76 & 4 & 6 & 6 & 17 & 17 \\
\hline Percentage & & $8 \%$ & $12 \%$ & $12 \%$ & $34 \%$ & $34 \%$ \\
\hline 20 & 9.09 & 6 & 28 & 6 & 5 & 5 \\
\hline Percentage & & $12 \%$ & $56 \%$ & $12 \%$ & $10 \%$ & $10 \%$ \\
\hline 21 & 7.26 & 6 & 24 & 10 & 6 & 4 \\
\hline Percentage & & $12 \%$ & $48 \%$ & $20 \%$ & $12 \%$ & $8 \%$ \\
\hline 22 & 9.95 & 1 & 10 & 6 & 22 & 11 \\
\hline Percentage & & $2 \%$ & $20 \%$ & $12 \%$ & $44 \%$ & $22 \%$ \\
\hline 23 & 7.23 & 0 & 11 & 6 & 22 & 11 \\
\hline Percentage & & $0 \%$ & $22 \%$ & $12 \%$ & $44 \%$ & $22 \%$ \\
\hline 24 & 6.35 & 17 & 16 & 0 & 11 & 6 \\
\hline Percentage & & $34 \%$ & $32 \%$ & $0 \%$ & $22 \%$ & $12 \%$ \\
\hline 25 & 5.17 & 3 & 7 & 16 & 16 & 8 \\
\hline $\begin{array}{l}\text { Total Mean } \\
\text { Score }\end{array}$ & & 6.76 & 16.17 & 8.12 & 13.32 & 5.64 \\
\hline Total SD & & 5.88 & 9.35 & 6.72 & 8.93 & 4.55 \\
\hline
\end{tabular}

The teachers' answer to the first item stating, "The textbook gives information, instruction or suggestions about how the book may be used and how the cultural content may be handled", was that 32 percent of the answers supported the idea that the books had clear instructions and guidelines on how to handle the cultural elements $(10 \%$ completely agree and $22 \%$ agree), while 34 percent of them disagreed with such idea ( $22 \%$ completely disagree and $12 \%$ disagree); hence, leaving the remaining 34 percent with no opinion. This means that the book was not successful in this regard.

The second item concerned if the textbook addresses specific learners and there are specific characters of the learners that the book addresses. According to the results observed in the above table, only 34 percent of the teachers agreed with this statement $(0 \%$ completely agree and $34 \%$ agree), whereas 22 percent of them had the opposite view $(10 \%$ completely disagree and $12 \%$ disagree). The remainder being $44 \%$ had no clear idea about this question. Once more, this indicated the weakness of the book to present a clear-cut message. The teachers' answer to the third item stating "The textbook suggests some roles for teachers in teaching " was that 100 percent of the answers supported the idea that the books suggest some roles for teachers in teaching ( $32 \%$ completely agree and $68 \%$ agree), while 0 percent of them disagreed with such idea.

The fourth item concerned if the textbook clearly introduces the target language culture. According to the results, 56 percent of the teachers agreed with this statement ( $12 \%$ completely agree and $44 \%$ agree), whereas 32 percent of them had the opposite view ( $10 \%$ completely disagree and $22 \%$ disagree). The remainder being $12 \%$ had no clear idea about this question. This indicated a partial success on the part of material developers to present a clear-cut message.

The teachers' answer to the fifth item stating "The textbook does not include generalizations about the culture (i.e. it informs the audience of the fact that what is true for one part is not necessarily true for the other parts) was that 56 percent of the answers supported the idea that the book does not include generalizations about the culture $(0 \%$ completely agree and $56 \%$ agree), while only 22 percent of them disagreed with such idea $(10 \%$ completely disagree and $12 \%$ disagree); hence, leaving the remaining 22 percent with no opinion. 
The sixth item concerned if the cultural language used in the textbook is comprehensible to EFL learners. According to the results, 56 percent of the teachers agreed with this statement (44\% completely agree and $12 \%$ agree), whereas 34 percent of them had the opposite view ( $0 \%$ completely disagree and $34 \%$ disagree). The remainder being $10 \%$ had no clear idea about this question.

The teachers' answer to the seventh item stating,"The Textbook promotes active student participation to communicate different values (i.e. mannerism, and courtesy)", was that 68 percent of the answers supported the idea that the books promote active student participation to communicate different values ( $12 \%$ completely agree and $56 \%$ agree), while only 32 percent of them disagreed with such idea ( $10 \%$ completely disagree and $22 \%$ disagree). The eighth item concerned if the cultural content includes generalization about the target culture(s). According to the results, only 34 percent of the teachers agreed with this statement ( $22 \%$ completely agree and $12 \%$ agree), whereas 22 percent of them had the opposite view ( $0 \%$ completely disagree and $22 \%$ disagree). The lion share of them, however, being $44 \%$ had no clear idea about this question.

The teachers' answer to the ninth item stating, "The textbook presents various cultural topics and themes" was that 46 percent of the answers supported the idea that the books present various cultural topics and themes $(12 \%$ completely agree and $34 \%$ agree), while 22 percent of them disagreed with such idea ( $0 \%$ completely disagree and $22 \%$ disagree); hence, only leaving the remaining 10 percent with no opinion.

The tenth item concerned if the textbook provides cultural topics in each and every lesson in all units. According to the results, only 22 percent of the teachers agreed with this statement (10\% completely agree and $12 \%$ agree), whereas 78 percent of them had the opposite view ( $12 \%$ completely disagree and $66 \%$ disagree).

The teachers' answer to the eleventh item stating,"The textbook provides sufficient details and information about the cultural topics" was that 38 percent of the answers supported the idea that the books provide sufficient details and information about the cultural topics ( $4 \%$ completely agree and $34 \%$ agree), while more than half of the teachers being 62 percent disagreed with such idea ( $18 \%$ completely disagree and $44 \%$ disagree).

The twelfth item concerned if the textbook includes variety of the world culture. According to the results, only 12 percent of the teachers agreed with this statement (4\% completely agree and $8 \%$ agree), whereas almost all of them being 88 percent had the opposite view ( $22 \%$ completely disagree and $66 \%$ disagree). This shows that book was by no means successful in presenting variety of the world culture(s).

The teachers' answer to the thirteenth item stating,"The textbook includes just specific cultures such as American or British culture" was that 78 percent of the answers supported the idea that the books include just specific cultures such as American or British culture (32\% completely agree and $46 \%$ agree), while 10 percent of them disagreed with such idea ( $0 \%$ completely disagree and $10 \%$ disagree); hence, leaving the remaining 12 percent with no opinion. This means that the book did include a lot of issues from American or British culture.

The fourteenth item concerned if the textbook represents real target language culture not the author's view. According to the results, only 34 percent of the teachers agreed with this statement ( $0 \%$ completely agree and $34 \%$ agree), whereas 22 percent of them had the opposite view ( $10 \%$ completely disagree and $12 \%$ disagree). The remainder being $44 \%$ had no clear idea about this question. This indicated the fact that there was no obvious answer to the question.

The teachers' answer to the fifteenth item stating, "The textbook does not provide any topics that might not be culturally suitable for the learners in class" was that 58 percent of the answers supported the idea that the do not provide any topics that might not be culturally suitable for the learners in class ( $12 \%$ completely agree and $46 \%$ agree), while 22 percent of them disagreed with such idea ( $0 \%$ completely disagree and $22 \%$ disagree); hence, leaving the remaining 10 percent with no opinion. This means that the textbook does not provide any topics that might not be culturally suitable for the learners in class to some extent. The sixteenth item concerned if the textbook provides adequate coverage of a variety of people and this is not limited to chosen people. According to the results, only 44 percent of the teachers agreed with this statement ( $22 \%$ completely agree and $22 \%$ agree), whereas 34 percent of them had the opposite view ( $22 \%$ completely disagree and $12 \%$ disagree). The remainder being $22 \%$ had no clear idea about this question.

The teachers' answer to the seventeenth item stating "The cultural information is not presented with comments such as being good or bad" was that 54 percent of the answers supported the idea that the cultural information is not presented with comments such as being good or bad (24\% completely agree and $32 \%$ agree), while only 22 percent of them disagreed with such idea (10\% completely disagree and 12\%disagree); hence, leaving the remaining 22 percent with no opinion. This means more than half of the teachers approved that the cultural information is not presented with comments such as being good or bad.

The eighteenth item concerned if the textbook advocates certain cultural values. According to the results, only 0 percent of the teachers agreed with this statement, whereas 68 percent of them had the opposite view $(22 \%$ completely disagree and $46 \%$ disagree). The remainder being $32 \%$ had no clear idea about this question. Once more, this indicated the books advocate no certain cultural values. The teachers' answer to the nineteenth item stating, "The textbook provides a balanced view of world culture" was that 20 percent of the answers supported the idea that the book provides a balanced view of world culture ( $8 \%$ completely agree and $12 \%$ agree), while 68 percent of them disagreed with such idea ( $34 \%$ completely disagree and $34 \%$ disagree); hence, leaving the remaining 12 percent with no opinion. This means that the book does not provide a balanced view of world culture. The twentieth item concerned if the textbook engages learners in cultural topics. According to the results, 68 percent of the teachers agreed with this statement (12\% completely agree and $56 \%$ agree), whereas 20 percent of them had the opposite view (10\% completely disagree and $10 \%$ disagree). The 
remainder being $12 \%$ had no clear idea about this question. This indicated the book engage learners in cultural topics. The teachers' answer to the twenty first item stating, "Learners are given opportunities to use their language ability to discuss cultural issues" was that 60 percent of the answers supported the idea that the books give learners opportunities to use their language ability to discuss cultural issues (12\% completely agree and 48\% agree), while 20 percent of them disagreed with such idea (12\% completely disagree and $8 \%$ disagree); hence, leaving the remaining 20 percent with no opinion. This means that the book gives learners opportunities to use their language ability to discuss cultural issue.

The twenty-second item concerned if the cultural activities provide students with opportunities to participate in games, songs, celebrations, sports, or entertainment representative of the foreign culture. According to the results, only 22 percent of the teachers agreed with this statement (2\% completely agree and $20 \%$ agree), whereas 66 percent of them had the opposite view ( $22 \%$ completely disagree and $44 \%$ disagree). The remainder being $12 \%$ had no clear idea about this question. This indicates that the cultural activities in the book provide students with few opportunities to participate in games, songs, celebrations, sports, or entertainment representative of the foreign culture.

The teachers' answer to the twenty third item stating, "The illustrations are self-explanatory and appropriate to learners' native culture" was that only 22 percent of the answers supported the idea that the illustrations are appropriate to learners' native culture ( $0 \%$ completely agree and $22 \%$ agree), while 66 percent of them disagreed with such idea ( $22 \%$ completely disagree and $44 \%$ disagree); hence, leaving the remaining 12 percent with no opinion. This means that the illustrations were not appropriate to learners' native culture to a great extent.

The twenty-fourth item concerned if characters represent different nationalities, countries, and the local society. According to the results, 66 percent of the teachers agreed with this statement (34\% completely agree and $32 \%$ agree), whereas 34 percent of them had the opposite view (12\% completely disagree and $22 \%$ disagree), indicting the fact that characters do not represent different nationalities, countries. The teachers' answer to the twenty fifth item stating, "illustrations tell us about the values of the social groups who adopt them" was that only 20 percent of the answers supported the idea that illustrations tell us about the values of the social groups who adopt them ( $6 \%$ completely agree and $14 \%$ agree), while 48 percent of them disagreed with such idea (16\% completely disagree and $32 \%$ disagree); hence, leaving the remaining 32 percent with no opinion. This means that illustrations do not provide much about the values of the social groups who adopt them.

In a nutshell, the highest mean score overall belonged to the Agree category $(16,17)$, with a 9.35 standard deviation score. The lowest mean score, however, belonged to the Completely Disagree category (5.64) and the SD of 4.55. Therefore, based on the data obtained via questionnaire, the teacher participants supported the idea that the Total English Series favored western cultures in general, which shows a hegemonic view all in all.

\section{Techniques and Strategies used by teachers}

The second research question concerned the way teachers expose students to cultural elements represented in Total English Series. The researcher's class observation schemes were analyzed to answer this question.

Based on the observation analyses, it was revealed the only three main techniques were utilized to expose learners to cultural elements. The techniques are as follows:

1) Conducting discussion on a cultural issue and providing them with extra information (awareness raising)

2) Asking students to search some issues online

3) Comparing and contrasting the local and target cultures

Here are two sample notes taken by the researcher-observer:

"The teacher contrasted and compared local culture with western cultures. She mentioned all cultural elements and gave learners an assignment of doing research to find some interesting differences in different countries all around the world."

"Most cultural elements were ignored. The activities were mostly focused on comparing and contrasting cultures."

As mentioned in the sample notes, teachers in class majorly ignored the cultural elements. Hence, the answer to the last research question would be the limited use of techniques and strategies to teach cultural elements of the book, along with the ignorance of the rest which might have been due to the lack of teachers' cultural awareness.

\section{Discussion and Conclusion}

Based on the data obtained via questionnaire, the teacher participants had a mixed view about their perception of cultural elements in the books. According to the data analyses, it was revealed that the western culture was the domineering category throughout the book, neglecting the local culture of language learners to a great extent. Besides, few techniques and strategies were used by teachers to give their students some cultural awareness.

This finding was in agreement with the studies carried out by Lee (2000) and Chen (2004). The textbook analysis in Lee (2000) and the survey of students' perception in Chen (2004) drew similar conclusions, that the majority of cultural contents had been predominantly devoted to target-culture learning. These results show a distinct conflict with many scholars' ideas in that source culture plays a more significant role in promoting language learners' intercultural communicative competence (Chastain 1988:303, Tomalin\&Stemple ski1993, Pulverness 1995). They maintain that the priority of culture learning should be given to source culture in the EFL classroom so as to equip 
language learners with intercultural communicative competence. To be exact, culture learning should aim at familiarizing learners with customs, habits, food, holidays, life-style, and generally-accepted world views, etc.

There are at least two possible reasons behind the inclination to the target culture from both textbook writers and students' points of view. The first reason might be from the orientation of education system of English teaching and learning in Iran. The arguments of what English as a subject should emphasize and what kinds of students it should foster have been discussed for a long time, since the disadvantages of examination-oriented instruction system of EFL in Iran have been felt gradually. In reality, it is very likely that language centers in Iran do not have any intention to perform at an intercultural communication level. As focused in the national curriculum for English institutes, English education should aim to enhance the students' Intercultural Communicative Competence (Education Ministry of Iran, 2000). However, students under an examination-oriented education system, EFL teaching and learning unduly values linguistic competence but neglects culture which comes with it. The students are highly motivated to achieve linguistic competence in order to achieve high scores in the tests. Iranian English teachers spend a lot of time to study how to transmit the contents and knowledge in the textbooks to students. Hence the students can achieve good points in the examinations in which the items are designed to have a close relationship to the textbook contents. Over $50 \%$ of the "notes" are related to world knowledge with the purpose of helping students to comprehend the meaning of tasks, so that they answer the exercises correctly. The negative effects of the traditional teaching methods on the students were also reflected in the present study. The majority of students thought that the current cultural learning was hindered by boring and uninteresting teaching methods". Thus, they preferred teachers to provide the cultural background and talk about current events related to cultural issues. Based on their needs, the students' preferences indicated that cultural teaching and learning were still unsatisfactory.

The second reason might be motivated by the traditional methods of English teaching and learning in Iran. In the history of English teaching and learning, Iran was dominantly grammar-oriented for a long time until the first movement towards communicative teaching and learning by language centers. This movement in Iran's teaching of EFL came from an educational problem that needed to be solved. This problem was the existing unsatisfactory results of the traditional grammar-oriented teaching method. Eighty-seven percent of teachers in Iran's middle schools adopted the traditional method for their teaching and focused only on grammar. As a result, the traditional method with the focus on facts and cultural knowledge only for the reading of literature produced unsatisfactory teaching results. Students became almost "deaf and dumb" and had little ability to speak and understand English (Tang \& Ng, 1997). However, because the communicative teaching method was new in every way, it met with considerable resistance from the start. As mentioned in their study, Campbell \& Zhao (1993) declared that many teachers have tried to change the dominant teaching procedures but quickly get frustrated, lose their initial enthusiasm, and acquiesce to the traditional methods.

In conclusion, the first research questions aimed to investigate teachers' perceptions and expectations of cultural contents and cultural learning in Total English book series. Firstly, the findings showed that the authors of Total English Series followed the traditional concept that linked English learning to English-speaking countries' cultures. Secondly, it was found that the percentage of target culture was higher than that of source culture by comparing all the themes. It can be inferred that the authors of the textbook may not have paid great attentions to the important role that source culture played in improving learners' communicative competence. Thirdly, the teachers' perceptions of the focuses in terms of the categories and themes under types of culture presented in Total English Series were basically correlated to the findings of textbook analysis. While teachers were expecting more source culture from the textbook, this suggests it may be considered that the local English textbook should bring more authentic source culture to fulfill the learners' needs.

The aim of the present study was to find out if some hegemonic cultural information about western countries is found in Total English textbooks. The aim was also to see if teachers find differences in the cultural content of the books.

The results of the study pointed out that the textbooks include significantly more hegemonic cultural content. This is rather surprising since it was expected that the textbooks would have improved in this respect since the importance of teaching different cultures is nowadays better acknowledged. It is of course possible that the other English-speaking cultures than eastern cultures have gotten more attention in the textbooks. Furthermore, the textbooks appear to include more stereotypes and hegemonic values highlighted in the textbooks.

What is more, by tapping into teachers' perception about cultural issues via a questionnaire, the researcher found out that the books do not follow the criteria for intercultural learning and that western culture is mostly highlighted. In addition, according to class observations, teachers in class and a limited range of techniques majorly ignored the cultural elements and strategies were used to teach cultural elements. It is worth mentioning that the ignorance of the cultural topics might have been due to the lack of teachers' cultural awareness.

\section{References}

Adaskou, K. Britten, D., \& Fahsi, B. (1990). Design decision on the culture content of a secondary English course for Morocco. ELT Journal, 44 (1), 3-10.

Al Migdadi, M. (2008). The Teaching Of English and its Culture in EFL Contexts: A CaseStudy Of English Language Instructors and Students in The Language Centre at Al Al-Bayt University, Jordan. Unpublished Ph.D. Thesis. International Islamic University -Malaysia. 
Apple, M. W. (1979). Official Knowledge: Democratic Education in a Conservative Age. New York: Routledge.

Asghari, S. (2011). The Compatibility of Cultural Value in Iranian EFL Textbooks. Journal of Language Teaching and Research, 2(4).

Brown, H. D. (2002). Principles of Language Learning and Teaching. Pearson Education: Longman.

Chastain, K. (1988). Developing Second Language Skills. Theory and Practice. Orlando, Florida: Harcourt Brace Janovich Publishers.

Chen, B. B. (2004). A survey on cultural learning and its variables analysis. Xi'an: Journal of Xi' an International Studies University, 12(3), 21-24.

Cortazzi, M., \& Jin, L. (1999). Cultural Mirrors, Materials and methods in the EFL classroom. In E. Hinkel (Ed.), Culture in Second Language Teaching and Learning. Cambridge University Press: USA.

Dalbani, D. (2004). Bridging the Cultural Gap in EFL Materials. Damascus University Journal for the Arts and Humanities 20, (1).

Dwiek, Bader, (2000). Bilingualism and the problem of linguistic and Cultural interference. In Alharbi, L and Azer, H. Arabic Language and Culture in Borderless World. Kuwait University.

Dweik, B. (2006). A Manual for Evaluating the Cultural Content of EFL Textbooks. 10th Annual ELT Conference, November 17, 2007.

El-Hussari, I. (2008). Promoting the Concept of Cultural Awareness as a Curricular Objective in an ESL/EFL Setting: A Case Study of Policy and Practice.1st Mediterranean Graduate Students Meeting in Linguistics 25-26 October 2007, Mersin, Turkey.

Hall, J. K. (2002). Teaching and Researching Language and Culture. Essex: Pearson Education Limited.

Harmer, J. (2001). The Practice of English Language Teaching. England. Pearson Education Limited.

Hinkel, E. (1999). Culture in Second Language Teaching and Learning. Cambridge: Cambridge University Press.

Joiner, E. (1974). Evaluating the cultural content of foreign- language texts. Modern Language Journal.58, 242244.

Kilickaya, F. (2006). Guidelines to evaluate cultural content in textbook The Internet TESL Journal. Retrieved April 25, 2006 from http://itself .org /Techniques/kilickaya-cultural content.

Kramsch, C. (2001). Language and Culture. Oxford. Oxford University Press.

Kramsch, C. (1998). Language and Culture. Oxford: Oxford University Press.

Lee, K-Y. (2009). Treating culture: what 11 high school EFL conversation textbooks in South Korea. English Teaching: Practice and Critique, volume 8, 76-96.

McLeod, B. (1980). The Relevance of Anthropology to Language Teaching: In K.Croft (ed). Readings on English as a Second Language: For teachers and Trainee Teachers.2nd edition, Boston: Kittle, Brown and Company.

Powell, R.G., \& Andersen, J. (1994). Culture and classroom communication, in Samovar, L.A and Porter, R.E.(eds) Intercultural Communication: A Reader, 7th.ed.Belmont, CA: Wadsworth Publishing Company.

Rajabi, s., \& Ketabi, S. (2012). Aspects of Cultural Elements in Prominent English Textbooks for EFL Setting. Theory and Practice in Language Studies, 2(4).

Shatanawi, M. (2005). The Cultural Dimension in TEFL: A Case Study of the Cutting Edge Series, Unpublished Ph.D. Dissertation. Amman Arab University for Graduate Studies. Jordan.

Syahrom A., (1995). Encounter of the Cultural Kind. A paper presented at the THAI TESOL Annual Conference, January 1995.

Zhang, X., \& Yan, Y. (2006). Culture Influences on English Language Teaching US-China Education Review 3(8), (Serial No.21). 


\section{Appendix 1}

\section{A. Rationale and Objectives}

1.The textbook gives information, instruction or suggestions about how the book may be used and how the cultural content may be handled.

2.The textbook addresses specific learners and there are specific characters of the learners that the book addresses.

3.The textbook suggests some roles for teachers in teaching.

4. The textbook clearly introduces the target language culture.

5.The textbook does not include generalizations about the culture (i.e. it informs the audience of the fact that what is true for one part is not necessarily true for the other parts).

B. Cultural Materials

6. The cultural language used in the textbook is comprehensible to EFL learners.

7. The Textbook promotes active student participation to communicate different values (i.e. mannerism, and courtesy).

8. The cultural content includes generalization about the target culture(s).

9. The textbook presents various cultural topics and themes.

10. The textbook provides cultural topics in each and every lesson in all units.

11. The textbook provides sufficient details and information about the cultural topics.

12.The textbook includes variety of the world culture.

13.The textbook includes just specific cultures such as American or British culture.

14.The textbook represents real target language culture not the author's view.

15.The textbook does not provide any topics that might not be culturally suitable for the learners in class.

16.The textbook provides adequate coverage of a variety of people and this is not limited to chosen people.

17.The cultural information is not presented with comments such as being good or bad

18.The textbook advocates certain cultural values.

19.The textbook provides a balanced view of world culture.

20.The textbook engages learners in cultural topics.

C. Class Activities and Cultural Activities

21. Learners are given opportunities to use their language ability to discuss cultural issues.

22. The cultural activities provide students with opportunities to participate in games, songs, celebrations, sports, or entertainment representative of the foreign culture.

D. Teaching Aids: Illustrations, Exercises, workbook \& Supplementary Materials.

23.The illustrations are self-explanatory and appropriate to learners' native culture.

24. The characters represent different nationalities, countries, and the local society.

25. The illustrations tell us about the values of the social groups who adopt them.

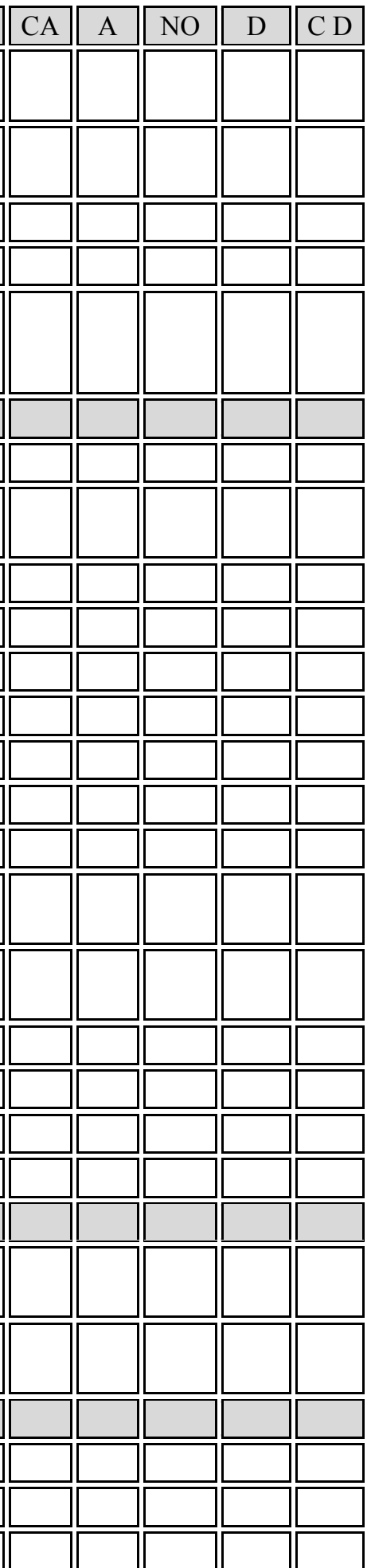


Appendix 2: Observation Scheme

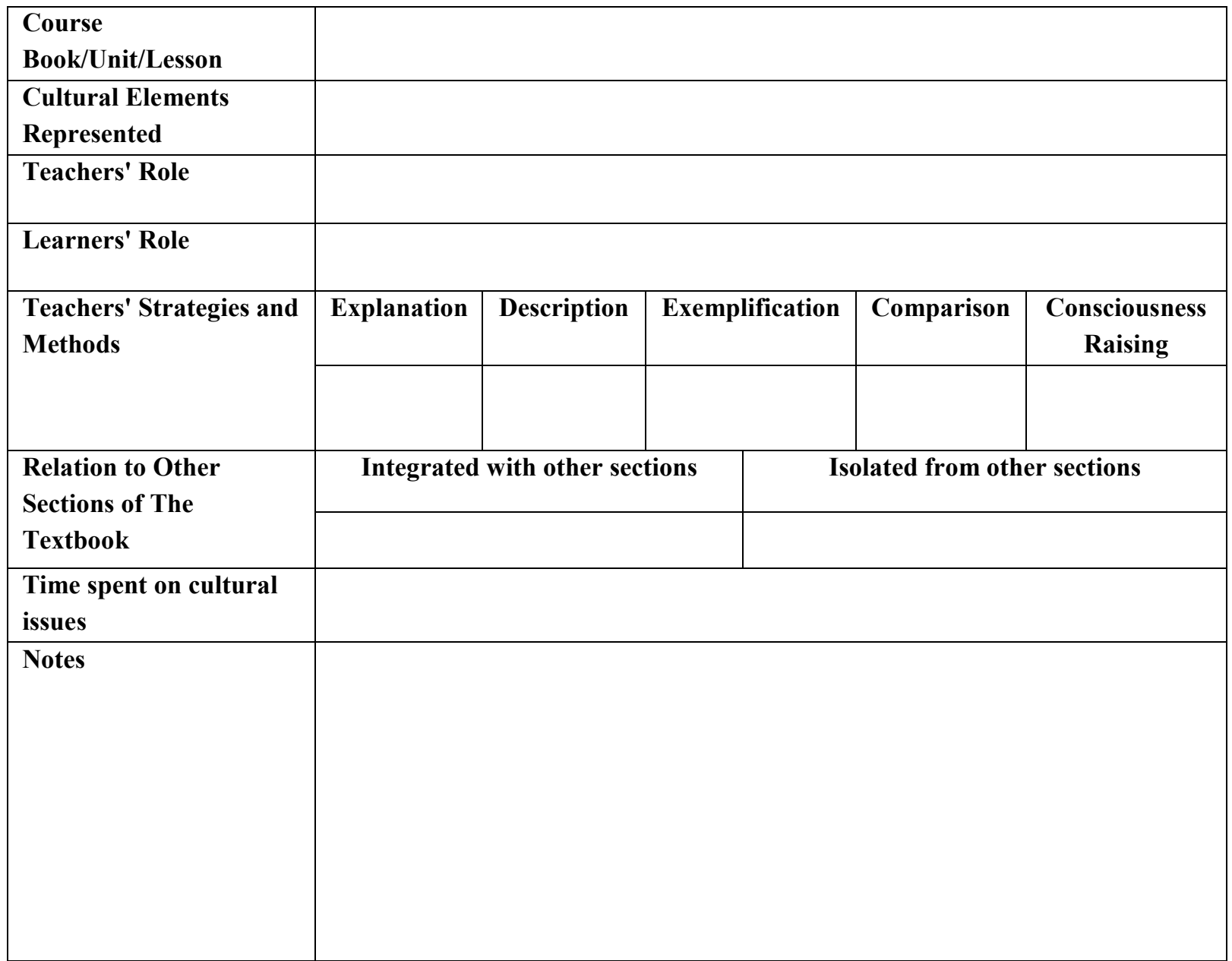

